\title{
Numerical models show coral reefs can be self-seeding
}

\author{
K. P. Black ${ }^{1}$, P. J. Moran ${ }^{2}$, L. S. Hammond ${ }^{1}$ \\ ${ }^{1}$ Victorian Institute of Marine Sciences, 14 Parliament Place, Melbourne, Victoria 3002, Australia \\ ${ }^{2}$ Australian Institute of Marine Science, PMB No. 3, Townsville MC, Queensland 4810, Australia
}

\begin{abstract}
Numerical models are used to simulate 3-dimensional circulation and dispersal of material such as larvae of marine organisms, on Davies Reef in the central section of Australia's Great Barrier Reef. Residence times on and around this reef are determined for well-mixed material and for material which resides at the surface, sea bed and at mid-depth. Results indicate order-of-magnitude differences in the residence times of material at different levels in the water column. They confirm previous $2-$ dimensional modelling which indicated that residence times are often comparable to the duration of the planktonic larval life of many coral reef species. Results reveal a potential for the maintenance of local populations of various coral reef organisms by self-seeding, and allow reinterpretation of the connectedness of the coral reef ecosystem.
\end{abstract}

\section{INTRODUCTION}

Hydrodynamic experiments of limited duration (Ludington 1981, Wolanski \& Pickard 1983, Andrews et al. 1984) have suggested that flushing times on individual reefs of Australia's Great Barrier Reef (GBR) are relatively short in comparison with the larval life of many different coral reef species (Yamaguchi 1973, 1977. Harrison et al. 1984, Munro \& Williams 1985), although Ludington's dye studies in the enclosed lagoon of One Tree Reef suggested residence times of the order of $5 \mathrm{~d}$. Consequently, self-seeding of reefs (i.e. larvae recruiting to the natal reef) has been considered improbable, notwithstanding occasional speculation about possible larval 'black holes' (Cheney 1974 , Johannes 1978) and gyres and eddies in the wake of reefs and islands (Hammer \& Hauri 1981, Wolanski et al. 1984a, Wolanski et al. 1984b).

However, 2-dimensional numerical simulations of the hydrodynamics and dispersal around reefs (Black \& Gay 1987a, b, 1990a, Black 1988, 1989) have predicted residence times that are longer than those suggested by field experiments, after the numerical simulations were validated by comparison with a series of detailed field experiments (Wolanski et al. 1984a, Willis \& Oliver 1988, Wolanski et al. 1989, Gay et al. 1990). Subsequent studies using the numerical models have made it possible to develop an understanding of the processes and their interactions which determine dis- persal of particles on reefs. They can be summarised as follows.

Circulation around the reefs is typified by a complex pattern of phase eddies (Black \& Gay 1987a, 1990a). These eddies and other components of the currents interact with the reef bathymetry to create a high level of horizontal mixing on and around the reefs (Black 1988). Consequently, the volume of material around a reef decays exponentially, with the time constant being a function of net volume flux passing the reef and the total volume of water on and around the reef (Black et al. 1990). The former depends on reef size and crosssectional area perpendicular to the net current. In quantitative terms, for typical weather and current conditions, average-sized reefs can retain larvae for periods in excess of $10 \mathrm{~d}$ (Black et al. 1990) even in the central GBR. For example, when modelling flow conditions measured during winter 1987 , up to $33 \%$ of neutrally-buoyant material released in the model on John Brewer Reef was still present 10 d later (Gay et al. 1990).

Furthermore, investigations of the relationship of the modelled hydrodynamics to larval dispersal revealed that when particles are retained for these durations, some locations retain more larvae or are visited more often by larvae than others (Black 1988). This was confirmed by the results of Willis \& Oliver (1988) who measured a variation in the numbers of coral larvae around Bowden Reef. Measured larval concentrations 
at 4 sites around the reef and in the lagoon corresponded with those predicted by the model. The highest concentration of larvae was predicted to occur in the southern compartment of the lagoon. High-frequency acoustic soundings subsequently identified a concentration of larvae on the lagoon side of the reef flat (Wolanski et al. 1989) at the location predicted by the model. Similar correspondence between initial sightings of aggregations of the crown-of-thorns starfish Acanthaster planci on individual reefs and concentrations of larvae predicted by the model was noted by Black \& Moran (1991).

The above findings derive from 2-dimensional modelling. However, if particles reside only at a particular level in the water column, through differences in specific gravity (e.g. Oliver \& Willis 1987) or active migration (e.g. Leis 1986), 2-dimensional circulation may not accurately represent passive dispersal. Accordingly, a 3-dimensional hydrodynamic and advection/dispersion model was established to assess the importance of 3-dimensional circulation for the residence times of particles representing (1) neutrally buoyant material or (2) material residing at the surface, mid-depths or near the sea bed.

Thus, the 3-dimensional modelling of a verticallyhomogeneous water column can be used to test whether different dispersal probabilities exist for organisms with neutrally-buoyant larvae or larvae which reside at a preferred level, either through specific gravity or behavioural differences. We interpret the results of this modelling in relation to the life history characteristics, biology and ecology of some of the major groups of coral reef organisms of the GBR.

\section{MODELLING}

The hydrodynamic model (3DD), a 3-dimensional model for vertically homogeneous conditions, is an extension of the 2-dimensional simulation 2DD (e.g. Black 1983, Black et al. 1989). The 3-dimensional nonlinear hydrodynamic equations are solved throughout the depth. In essence, the 3-dinensional model can be coded as a series of 2-dimensional models placed on top of each other, with the non-linear convective momentum term and the vertical eddy viscosity linking the layers. The equations solved are,

$$
\begin{aligned}
& \frac{\partial U}{\partial t}+U \frac{\partial U}{\partial x}+V \frac{\partial U}{\partial y}+W \frac{\partial U}{\partial z}-f V= \\
& \quad-g \frac{\partial \xi}{\partial x}+A_{H}\left(\frac{\partial^{2} U}{\partial x^{2}}+\frac{\partial^{2} U}{\partial y^{2}}\right)+\frac{\partial}{\partial z}\left(N_{z} \frac{\partial U}{\partial z}\right) \\
& \frac{\partial V}{\partial t}+U \frac{\partial V}{\partial x}+V \frac{\partial V}{\partial y}+W \frac{\partial V}{\partial z}+f U=
\end{aligned}
$$

$$
\begin{gathered}
-g \frac{\partial \xi}{\partial y}+A_{H}\left(\frac{\partial^{2} V}{\partial x^{2}}+\frac{\partial^{2} V}{\partial y^{2}}\right)+\frac{\partial}{\partial z}\left(N_{z} \frac{\partial V}{\partial z}\right) \\
W=-\frac{\partial}{\partial x} \int_{h}^{z} U \mathrm{~d} z-\frac{\partial}{\partial y} \int_{h}^{z} V \mathrm{~d} z
\end{gathered}
$$

At the surface, $z=\xi$,

$$
\frac{\mathrm{D} \xi}{\mathrm{D} t}=W
$$

where $t=$ time; $U, V=$ velocities in the $x, y$ directions respectively at elevation $z_{i} W=$ vertical velocity in the $z$ direction (positive upward) at the top of each layer; $h=$ depth; $g=$ gravitational acceleration; $\xi=$ the sea level above a horizontal datum; $f=$ Coriolis parameter; $A_{\mathrm{H}}=$ horizontal eddy viscosity coefficient; and $N_{z}=$ vertical eddy viscosity coefficient.

Surface boundary conditions at $z=\xi$ are

$$
\rho\left(N_{z} \frac{\partial U}{\partial z}\right)=\tau_{x}{ }^{s} \quad \rho\left(N_{z} \frac{\partial V}{\partial z}\right)=\tau_{y}{ }^{s}
$$

where $\tau_{x}{ }^{s}, \tau_{y}{ }^{s}$ denote the components of wind stress and

$$
\tau_{x}{ }^{s}=\rho_{\mathrm{a}} \gamma|S| S_{\mathrm{x}} \quad \tau_{y}{ }^{\mathrm{s}}=\rho_{\mathrm{a}} \gamma|S| S_{y}
$$

where $\rho=$ water density; $S=$ wind speed at $10 \mathrm{~m}$ above sea level while $S_{x}$ and $S_{y}$ are the $x$ and $y$ components; $\gamma=$ wind drag coefficient; $\rho_{a}=$ density of air.

At the sea bed, $z=h$, we have

$$
\rho\left(N_{z} \frac{\partial U}{\partial z}\right)=\tau_{x}{ }^{h} \quad \rho\left(N_{z} \frac{\partial V}{\partial z}\right)=\tau_{y}{ }^{h}
$$

where $\tau_{x}{ }^{h}, \tau_{y}{ }^{h}$ denote the components of bottom stress. Applying a quadratic law at the sea bed,

$$
\begin{aligned}
& \tau_{x}{ }^{h}=\rho g U_{h}\left(U_{h}{ }^{2}+V_{h}{ }^{2}\right)^{1 / 2} / C^{2} \\
& \tau_{y}{ }^{h}=\rho g V_{h}\left(U_{h}{ }^{2}+V_{h}{ }^{2}\right)^{1 / 2} / C^{2}
\end{aligned}
$$

with $U_{h}, V_{h}=$ the bottom currents; and $C=$ Chezy's $C$. For a logarithmic profile,

$$
C=18 \log _{10}\left(0.37 \mathrm{~h} / \mathrm{z}_{\mathrm{o}}\right)
$$

where $z_{0}=$ roughness length

The form of the horizontal eddy viscosity term results when the depth is presumed constant before taking the derivative of the horizontal shear stresses. The term, as presented, behaves as a velocity smoothing algorithm (Black 1989).

A staggered finite difference grid is utilised similar to that applied by Leendertse \& Liu (1975) which places the $V$ and $U$ components on 'north and south' walls of each grid box respectively. $W$ is located in the centre of the 'top' wall. The sea level replaces W in the top layer. The solution is found by time stepping with an explicit solution, as employed in 2DD.

Data were not available for a fully stratified, density- 
driven coupled simulation (e.g. Black 1990). Thus, the model is relevant to vertically unstratified hydrodynamics only. This does not preclude treatment of marine organisms which have a tendency to reside at favoured levels in the water column. The fully stratified coupled model will await shelf-scale data specifying the dynamics of such conditions. The measurements of Gay et al. (1990) around John Brewer Reef indicated that significant stratification on the continental shelf surrounding the reef was uncommon, although Wolanski et al. (1989) noted stratification in the lagoon of Bowden Reef and Andrews \& Gentien (1982) identified a colder layer of near-bed water on the shelf of the central GBR. Wolanski \& Hamner (1988) presented temperature contours in mid-summer from a reef lagoon which showed a temperature difference of $0.6^{\circ} \mathrm{C}$ between the surface and the bed.

Because the 3 -dimensional model is composed of a vertical stack of 2-dimensional simulations, many of the techniques applied in the 2-dimensional model (Black \& Gay 1987b) could be used without modification. These included application of a body force to drive the coastal currents and a force to balance the Coriolis force acting on the coastal currents. In reality, the Coriolis force is, on average, in balance with a crossshelf sea gradient against the Queensland coast (Burrage pers. comm.) but the coast was outside the fine model grids employed in this study and so the sea gradient had to be separately represented.

Taking an orthogonal coordinate system aligned such that $x$ is directed offshore and $y$ is parallel with the coast, the body forces $\left(F_{x}, F_{y}\right)$ can be obtained from the hydrodynamic equation (Eqs. $1 \& 2$ ) and are

$$
\begin{gathered}
F_{x}=-\left(f V+W_{x}\right) \\
F_{y}=g \frac{\partial \xi_{\mathrm{c}}}{\partial y}-W_{y}+\frac{g V}{C^{2} h_{\mathrm{av}}}\left(0.5 U_{\mathrm{T}}^{2}+V^{2}\right)^{1 / 2}
\end{gathered}
$$

The current $V$ is directed shore-parallel; the perpendicular tidal current has maximum magnitude $U_{\mathrm{T}} ; \xi_{\mathrm{c}}=$ sea gradient driving a longshore current; $W_{x}, W_{y}=$ vertically-averaged wind stress terms; and $h_{\mathrm{av}}=$ average depth in the model grid. The body force in the $x$ direction does not drive a current, but represents the sea gradient perpendicular to the coast which balances the Coriolis force associated with the longshore current. The longshore body force groups together all the forces which drive a current along the shelf and acts as a sea gradient substitute. The body force equations (Eq. 10) allow one to calculate (1) the total longshore current and (2) the resulting cross-shore sea gradient, for a particular wind condition and longshore sea gradient (or associated current), prior to the commencement of the model simulation.

The method is validated when the residual current in the model equals the required input value in mag- nitude and direction. This was always checked after each simulation, confirming that the method was entirely satisfactory. In addition, a crescentic/lagoonal bathymetry was simulated (1) with a sea gradient applied at the open boundaries to drive a current and (2) with the sea gradient replaced with an equivalent body force. The results obtained showed that the 2 methods were equivalent, as expected.

The body forces represent the average condition over the entire model grid and are calculated using $h_{a v}$. However, as the wind stress is depth-dependent, it is still necessary to calculate wind stress in each model cell. The wind stress applied in the cell is the difference between the average stress incorporated in the body force and the actual stress at the cell in question. Thus,

$$
W_{y}^{\prime}=\rho_{\mathrm{a}} \gamma|S| S_{Y}\left(1 / h-1 / h_{\mathrm{av}}\right) / P
$$

Bed friction, horizontal eddy viscosity and surface wind stress were unchanged from the 2-dimensional model runs of Black et al. (1990) and Black (1989). However, a value of the vertical eddy viscosity was required. This was set to a constant value of $0.004 \mathrm{~m}^{2} \mathrm{~s}^{-1}$. The same sea level boundaries and bathymetry were used in both models.

\section{Advection/dispersion model}

The Lagrangian advection/dispersion model 2AD was extended to treat the vertical dimension (now Model 3AD). The model treats the transport of larvae in a direct fashion by assigning a particle with position $X=X(x, y, z, t)$ to represent each larva which is tracked in space and time as it advects with the currents predicted by the hydrodynamic model. To prevent particles moving off circular streamlines, a truly secondorder accurate advection scheme was developed (Black \& Gay 1990b). This scheme was applied in 3AD, but the advection was taken to first-order accuracy only, in the vertical dimension.

The second order scheme is

$$
\begin{aligned}
& \delta_{x}=\frac{\left(u^{\prime}+\left(u_{y} v^{\prime}-v_{y} u^{\prime}\right) \delta t / 2\right) \delta t}{\left(1-u_{x} \delta t / 2\right)\left(1-v_{y} \delta t / 2\right)-u_{y} v_{x} \delta t^{2} / 4} \\
& \delta_{y}=\frac{\left(v^{\prime}+\left(v_{x} u^{\prime}-u_{x} v^{\prime}\right) \delta t / 2\right) \delta t}{\left(1-u_{x} \delta t / 2\right)\left(1-v_{y} \delta t / 2\right)-u_{y} v_{x} \delta t^{2} / 4}
\end{aligned}
$$

where

$$
\begin{aligned}
& u^{\prime}=u+\delta t u_{t} / 2 \\
& v^{\prime}=v+\delta t v_{t} / 2
\end{aligned}
$$

and $u, v=$ orthogonal velocity components; $t=$ time; $\delta t$ is the model time step; $u_{x}, v_{x}=u$ and $v$ spatial velocity gradients; and $u_{t}, v_{t}=$ temporal gradients. In the simulations, $u_{t}$ and $v_{t}$ were secondary corrections and were neglected. 
Horizontal diffusion was modelled as a random walk with separate longitudinal and lateral coefficients set to simulate random turbulence, and vertical shear in the 2 -dimensional model. The distance increments (parallel with and perpendicular to the velocity characteristic) each time increment were

$$
\Delta x= \pm A_{1}|\vec{U}| \delta t_{i} \quad \Delta y= \pm A_{2}|\vec{U}| \delta t
$$

where $A_{1}, A_{2}=$ longitudinal and lateral coefficients; and $|\vec{U}|$ is the absolute value of the vector velocity. The sign $( \pm)$ is generated randomly. The effective diffusivity is thus scaled by instantaneous velocity. In the 3-dimensional model, the coefficients were both taken as 0.1 , i.e. the diffusivity distance increment was equal to $10 \%$ of the distance moved. Dyer (1973), for example, noted that turbulent fluctuations in tidal currents are often about $10 \%$ of the current strength. In a 2-dimensional model, the longitudinal coefficient was increased to 0.4 to parameterise the effect of vertical shear in the bottom boundary layer. The parameterisation factor was specifically determined for GBR conditions by varying the coefficient in a 2-dimensional model until the particle spread with time was similar to that obtained with the 3-dimensional model.

To treat the vertical movement, a sigma coordinate transformation was applied to the vertical particle position, i.e. $Z=z / h$, where $z$ is the position in the original orthogonal coordinate system. The sigma transformation prevented particles from 'grounding' over steep bathymetry, which was particularly prevalent when a first-order accurate advection scheme was applied.

To model the well-mixed case, each particle was assigned a random vertical coordinate after each model time step. In the well-mixed condition, the vertical position of the particle is physically irrelevant, except that the particle must experience the currents at each level for an equal amount of time, and this is ensured by the random location method. The nomixing case was simulated by taking the vertical diffusivity as zero. Particles then moved vertically by advection only.

To specify particle retention rates, particles were released on and around the reef over one tidal cycle and then allowed to drift freely with the currents. Retention rates were then determined by counting the number remaining on and around the reef with time.

In the simulations, particles were conserved, as they would be for any conservative, neutrally-buoyant particle in the natural environment. Non-conservative cases occur in nature. For example, predation or coliform die-off are two of a number of processes which could result in the loss of particles from the system. However, the conservative results are equally relevant to the passage of any neutrally-buoyant material, e.g. pollutants, nutrients or neutral larvae, and die-off or predation rates can be applied to the predicted rates once data becomes available.

\section{Model simulations}

Our primary purpose in this paper is to examine the 3-dimensional effects, rather than the influence of current and weather variability around a variety of reefs. Thus, the following discussion deals with a case study of one actual reef, Davies Reef in the central GBR.

The tide at Davies Reef consists of an input wave which crosses the shelf moving approximately normal to the coast (Church et al. 1985) and a reflected output wave, combining to create a standing pattern. Accordingly, the tidal boundary conditions included both the input and output waves with relative phases selected to ensure that the peak current strength in the free stream away from the reef equalled values measured in the vicinity of Davies Reef (Black \& Gay 1987b).

Quasi-steady shelf currents (denoted as 'coastal' currents in this paper) are typically about $0.12 \mathrm{~m} \mathrm{~s}^{-1}$ and parallel to the coast (Andrews 1983). These are associated with the East Australian Current (EAC) modulated by direct local wind action (Andrews \& Gentien 1982, Andrews \& Bode 1988). Winds are typically 5 to $7 \mathrm{~m} \mathrm{~s}^{-1}$ east to southeast trades but, in summer, winds from the northerly quadrant (Pickard et al. 1977) also are common.

For comparative purposes, Davies Reef was modelled in 2 and 3 dimensions using the same input conditions. Tides of $\mathrm{M}_{2}$ frequency and constant amplitude were modelled, so that diurnal tidal inequalities were not treated. However, separate tests indicated that diurnal inequalities have an insignificant influence on dispersal over periods of days to weeks (Black unpubl.). We modelled a spring tidal range, a poleward current of $0.2 \mathrm{~m} \mathrm{~s}^{-1}$, partially negated by a $5 \mathrm{~m} \mathrm{~s}^{-1}$ trade wind from $120^{\circ} \mathrm{T}$.

The model horizontal grid size was $400 \mathrm{~m}$ square, which resolved all the major features of the reef. Sensitivity tests of model grid size indicated that 10 to 20 cells across the reef were needed to effectively simulate the eddies in the lee of the reef, and to effectively model the particle retention. In the direction perpendicular to the coastal currents, Davies Reef is $6 \mathrm{~km}$ (or 15 cells) long. In the vertical dimension, a 7 -layered 3-dimensional model was constructed with the layer interfaces at $0.2,2,7,27,47,52$ and $55 \mathrm{~m}$ below the surface datum. The continental shelf depth was $55 \mathrm{~m}$ around Davies Reef and mean sea level was $1.4 \mathrm{~m}$ above datum. 


\section{Calibration and verification}

The 2-dimensional model has been applied to a number of locations where good quality data were available for its verification (e.g. Black et al. 1989). The physical coefficients for the GBR were initially established by comparison with values from similar environments, and it was found that the bed friction required special care (Black \& Gay 1987b). To specify the bed roughness, 3 different techniques were applied. First, wave height measurements over a coral reef in Hawaii were numerically simulated and friction obtained from the rate of height attenuation. The roughness was then estimated using direct measurements of bed undulations and from vertical velocity profiles recorded over a coral bed on Little Broadhurst Reef. The model was calibrated and verified and the selection of physical coefficients confirmed during 3 independent simulations of GBR reefs. The simulations were confirmed against measurements from (1) Davies Reef (Black \& Gay 1990a) (2) Rattray Island (Black 1989) and (3) John Brewer Reef (Gay et al. 1990). The specification of bed friction is presented by Black \& Gay (1990a) and Gay et al. (1990) and horizontal eddy viscosity is treated by Black (1989). During this period, the same model was also applied by Sammarco \& Andrews (1988) to Helix Reef, a small reef in the central GBR, using the same coefficients and techniques developed by Black \& Gay (1987b). In this paper, we use these 2-dimensional model results to confirm the vertically-averaged behaviour of the 3-dimensional model.

While some error may still be present, the authors note that a variety of data have been analysed and successive calibrations have been undertaken. The calibrations demonstrated that bed friction on the reef flat was highly important, affecting flow on the reef flat and in the lagoon, and that further hydrodynamic data on coral reef flats may help to refine the frictional resistance. Wave/current interaction in the bottom boundary layer on the reef flat would also influence the frictional retardation, and the waves themselves generate a current into the lagoon. A simple schematic numerical test of the importance of these currents indicated that flows across the reef flat can lengthen residence times.

No experiments of sufficient detail were available to calibrate the dispersal model. However, the dispersal model relies almost entirely on flow velocities to determine advection and the highly important process of advective diffusion. Model tests with significantly different coefficients representing eddy diffusivity (Eq. 15) showed that the choice of coefficient values had only a small influence on the retention times. For example, when the coefficients $A_{1}, A_{2}$ were altered from 0,0 to $1,0.25$ the percentage of particles remaining on the reef during a $10 \mathrm{~d}$ period differed by a maximum of $7 \%$ only. These results indicate that the dispersal model, when used for the purpose of predicting reef-scale residence times, is effectively calibrated once the hydrodynamics have been calibrated. As previously noted, 3 separate simulations of GBR reefs were made to calibrate the coefficients in the hydrodynamic models.

\section{RESULTS}

The circulation predicted by the 3-dimensional model after averaging the currents in the layers is very similar to the vertically-averaged currents obtained
Fig. 1. Comparison of the 2-dimensional model flow patterns with the verticallyaveraged velocities obtained from the 3 dimensional model, near peak flow on Davis Reef

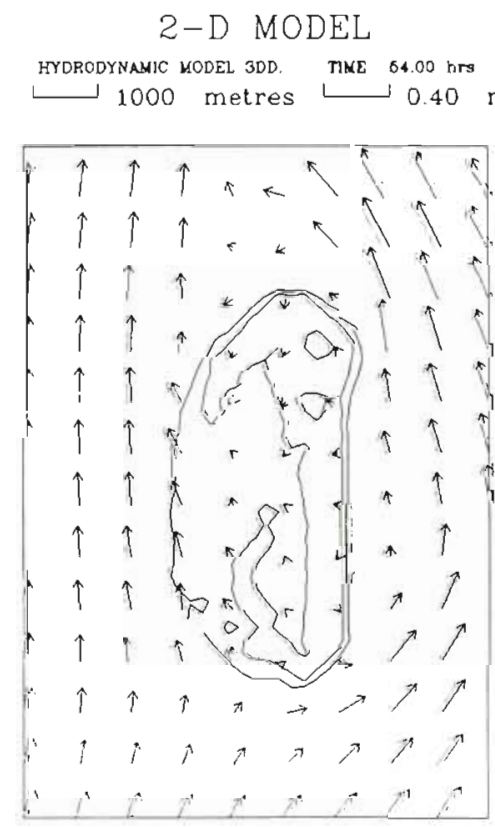



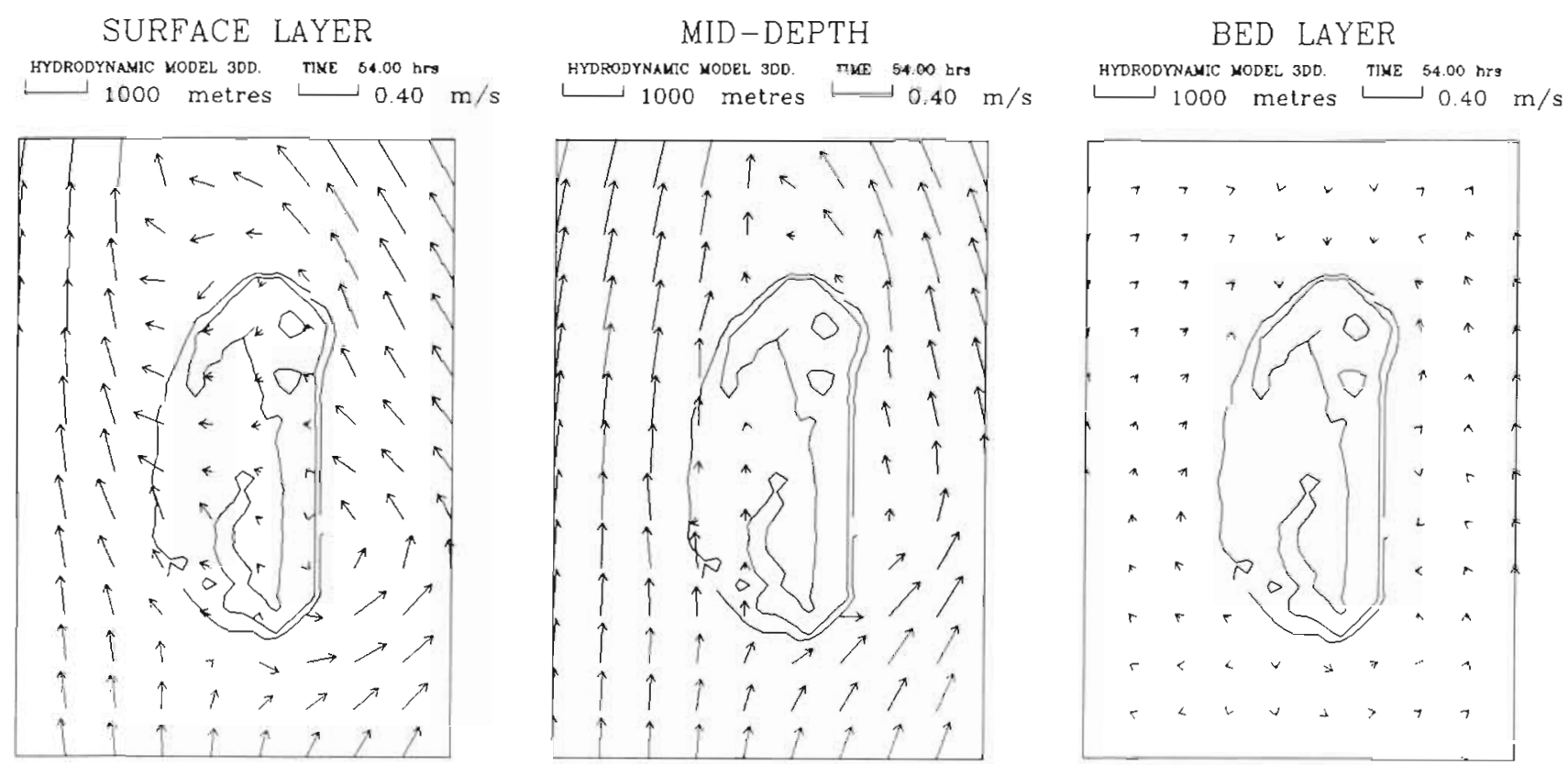

Fig. 2. Davis Reef flow patterns at $54 \mathrm{~h}$ at the surface, mid-depth and the sea bed from the 3-dimensional model. Only every second vector has been plotted for clarity

from the 2-dimensional model (Fig. 1). As would be expected in a homogeneous water column, the 3 dimensional model incorporates the 2-dimensional results, but additionally provides details of the variation of circulation through the vertical. The null result, in fact, confirms the general behaviour of the 3-dimensional model (Fig. 1).

An example of the currents in the vertical layers (Fig. 2) shows that, in the surface layer, the flows on and near the reef are deflected downwind, the current being a resultant of the combination of tidal and wind-driven surface flows. At mid-depth however, the tidal flow dominates and currents are primarily a response to the tidal sea gradients guided by the topography along the reef face. Mid-depth flows are very similar to the 2-dimensional vertically-averaged model results. Mid-depth currents in the lagoon are nearly perpendicular to the surface current and, adjacent to the reef, currents are faster than at the surface where the interaction with the opposed wind stress reduces the current in the surface layers.

A developing eddy is evident to the north of the reef at all levels. Black \& Gay (1987a) noted that the eddies on the GBR (in unsteady tidal currents) are strongly dependent on horizontal variations in velocity phase. Because friction plays a minor role on the continental shelf, currents take about $2 \mathrm{~h}$ to reverse after the tidal sea surface gradient changes sign. However, in the sheltered lee of the reef where the flows have little inertia, the currents are more in phase with the changing sea gradient, and an eddy develops (denoted as a phase eddy).
With the 3-dimensional model, the vertical structure of the eddy can be seen. Currents heading towards the south at bed level are directed towards the northwest at mid-depth in the eddy (Fig. 2). This occurs because bed friction acts more quickly at the bed than in the upper layers. Thus, the bed currents respond to the change in sea gradient sooner, while the upper layers in the eddy are still decelerating. Consequently, southerly currents occur at the bed and northwesterly flows occur at middepth to the north of the reef (Fig. 2).

\section{Retention rates}

The retention rates of vertically well-mixed particles were very similar using either the 2 - or 3-dimensional

$$
\text { 2-D AND 3-D MODELS }
$$

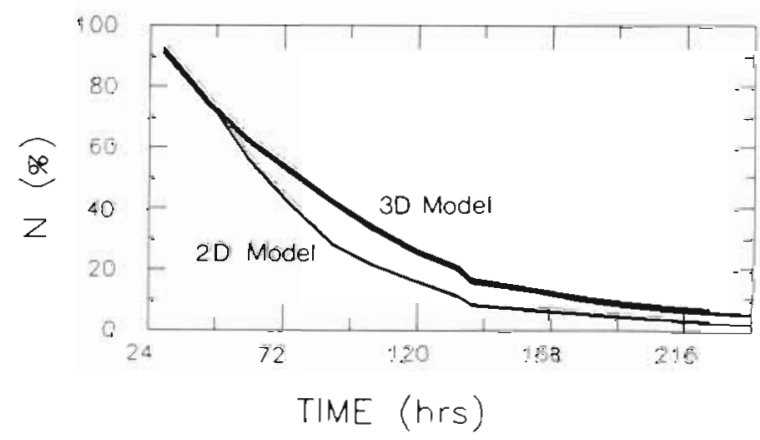

Fig. 3. Comparison of particle numbers remaining against time using velocities from the 2 - and 3-dimensional models 


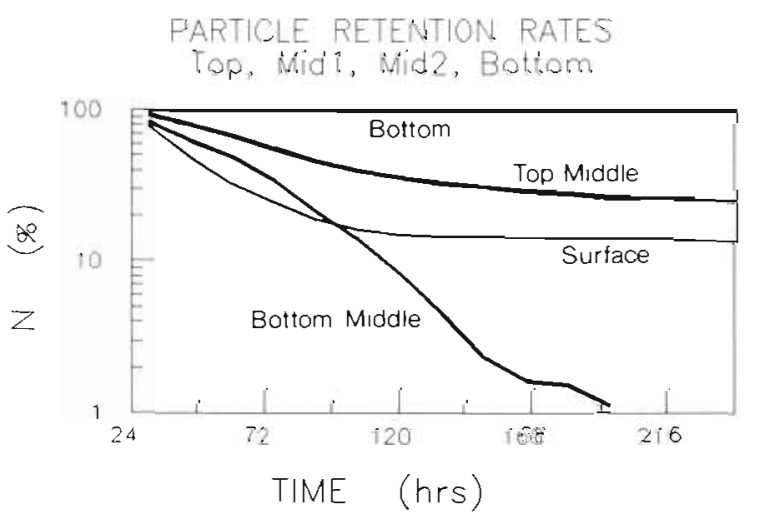

Fig. 4. Particle numbers remaining in the region of the reef against time at the surface, upper middle layer, lower middle layer and the sea bed

model (Fig. 3). This arises because of the similarity of the vertically-averaged flow patterns obtained with the 2- and 3-dimensional models (Fig. 1), as expected for a homogeneous ocean. Approximately $20 \%$ of well-mixed particles remain after $5 \mathrm{~d}$ and $5 \%$ after $10 \mathrm{~d}$.

The 3-dimensional model, however, provides additional insights for those cases where particles may reside at a preferred level. The retention rates in the surface layer, 2 mid-depth layers and the bottom layer were considerably different (Fig. 4). The surface layer initially decays fastest, but is eventually overtaken by one of the mid-depth layers. This occurs because the wind and coastal currents are opposed. Thus, material is swept away by the wind-driven current in the surface layer. Further down in the water column (Top Middle) the wind-driven current and coastal current are more nearly in balance and material is lost slowly. Below this level, the wind-driven current is less effective and material is removed by the coastal current (Bottom Middle). Finally, near the sea bed, the reduction of currents in the boundary layer due to bed friction causes retention to increase again and there is high retention at bed level. More than $95 \%$ of particles are still present after $10 \mathrm{~d}$ near the bed.

Reefs of a similar size and similar exposure to coastal currents as Davies Reef (about $6 \times 3 \mathrm{~km}$ ) will commonly retain about $10 \%$ of particles 5 to $15 \mathrm{~d}$ after spawning in typical coastal current conditions (Black et al. 1990). Many more particles will be retained in periods when coastal currents are small. Thirteen per cent of particles were still present on Davies Reef after $6 \mathrm{wk}$ in one simulation with a coastal current of $0.05 \mathrm{~m}$ $\mathrm{s}^{-1}$. Similar results were obtained for other reefs on the GBR although the smallest reefs (e.g. Helix Reef which is planar and roughly circular with a diameter of $600 \mathrm{~m}$ ) had a significantly reduced residence time (Black et al. 1990).

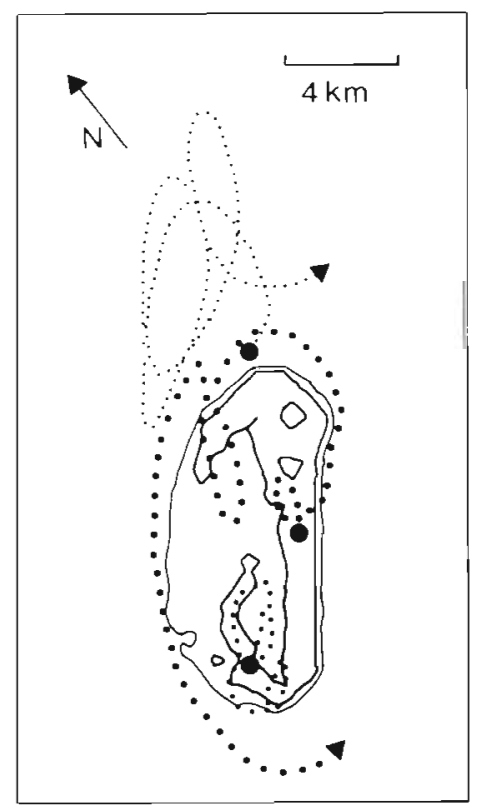

Fig. 5. Tracks over $38 \mathrm{~h}$ of particles released at 3 locations ( $\bullet$ on Davies Reef for a simulation with coastal currents of $0.05 \mathrm{~m}$ $\mathrm{s}^{-1}$ Individual particles moved over large areas, but were trapped within a dynamic environment which includes the surrounding waters. One particle released on the reef flat travelled around the reef perimeter and re-entered the lagoon on the lee side

\section{DISCUSSION}

\section{Processes causing particle retention}

Circulation around the reefs is characterised by high horizontal shear due to velocity phase differences on and around the reef throughout the tidal cycle (Black 1988). This process is illustrated by the tracks of 3 particles released from different locations on Davies Reef (Fig. 5) which moved over a large area and, on occasion, overlapped. One of the particles moved over the reef flat from the lagoon, but subsequently returned to the lagoon, entering at the lee side of the reef. Similar behaviour was observed during experiments at John Brewer Reef when a drogue placed in the out-flowing northern entrance of the reef re-entered the lagoon across the reef flat $1200 \mathrm{~m}$ away 3 h later (Black \& Gay 1987b). The third particle remained in the south of the lagoon.

The well-mixed nature of the reef waters led Black et al. (1990) to postulate that the major cause of particle retention was the mixing process. The reef residence times were then related to the ratio of exchanged volume and the volume contained in the region indicated by the particle excursions in Fig. 5. Because of the similarity between the decay rates of neutrally buoyant particles obtained using the 2-and 3-dimensional models, the results presented in this paper indi- 
cate that the analytical formula of Black et al. (1990) remains relevant to the 3 -dimensional verticallyhomogeneous case for well-mixed material and that it continues to explain the main cause of particle retention on and around reefs.

Other factors play a role within the well-mixed zone. For example, particles can also be retained if their residual path (averaged over one tidal cycle) is closed or nearly closed. An example of this is seen in Fig. 5 at the southern end of Davies Reef lagoon where particles merely circulate around a closed loop and are lost only when random diffusion moves them off their trajectory. This is to be distinguished from a location where the Eulerian residual (the vector average of velocity passing a point in space over one tidal cycle) is small and from locations where larvae are retained in permanent quiescent zones or gyres (Cheney 1974, Johannes 1978, Hamner \& Hauri 1981). As the tidal excursion is comparable with the reef dimensions and tidal flows are fast at all locations around a reef at some stage during the tidal cycle, particles are not necessarily expected to be permanently retained in a zone of low Eulerian residual. However, eddies assist the retention process by returning some particles which would otherwise have been swept away, and, on occasions, by creating a closed or nearly closed 'Lagrangian' orbit for the particle over the tidal cycle. Thus, retention may occur even at points where currents or Eulerian residual flows are large.

Although the locations will vary with coastal current intensity, Black (1988) indicated that the zones of highest retention around a reef subjected to perpendicular tidal and coastal currents are most likely to occur on the downstream side of the reef, rotated clockwise from the major tidal axis. Notably, this location is not directly in the wake of the coastal current (Black 1988, Gay et al. 1990).

Black \& Moran (1991) found a correspondence between the locations of highest relative numbers and sites where infestations of crown-of-thorns starfish initially occurred. A second corroboration was found by Willis \& Oliver (1988) who recorded variability in Iarval numbers around a reef. Their measurements corresponded with model predictions of larval numbers (Black 1988) when dispersal was simulated using the environmental conditions present during the time the measurements were made.

Other, smaller-scale processes play roles. Non-linear interaction through the quadratic bed friction term and wave-driven currents modify the retention times by creating a blockage to the passage of coastal currents across the reef flat. Waves are especially important when winds, and therefore waves, are opposed to the coastal current. The importance of sea bed friction is clearly dependent on the percentage of time spent by an organism near the bed.
Thus, a number of factors contribute to the retention of larvae on and around reefs. However, reef flushing times of well-mixed particles are primarily related to the volume exchanged as coastal currents pass the reef. Embedded within an overall well-mixed region around the reef are a number of zones of relatively high retention formed by links with other regions, and interactions of the coastal and tidal currents with the reef morphology. 'Rules-of-thumb' to locate these zones suggest that they occur clockwise of the major tidal axis, in the central GBR where tidal currents run across the shelf perpendicular to the coastal currents.

\section{Implications for coral reef species}

Several aspects of the biology of coral reef organisms can be expected a priori to have a direct bearing on their probabilities of dispersal from the parent reef: the duration of planktonic larval life, the level which the larvae occupy in the water column, and the timing of spawning relative to the lunar tidal cycle.

Most species in the major groups of organisms on coral reefs (e.g. corals, fish and echinoderms) spawn in summer in the southern hemisphere (between October and January). The larvae typically spend from 2 to $8 \mathrm{wk}$ in the water column before settling. Corals, the majority of which are broadcast spawners, have a planktonic larval period of generally 2 to $6 \mathrm{wk}$ (Harrison et al. 1984); even those which brood their progeny may have larval lives of as long as 2 to 3 wk (Fadallah 1983). While data for other coral reef species are relatively few, it appears that the larvae of fish and those of echinoderms (particularly asteroids) spend 2 to $12 \mathrm{wk}$ (Sale 1980, Munro \& Williams 1985), and 2 to $4 \mathrm{wk}$ (Yamaguchi 1973,1977, Olson 1987) respectively in the plankton.

Thus, the results in this paper indicate that the larval life of many coral reef species can be of similar duration to the flushing times for individual coral reefs. This means that larvae may be retained on or around the natal reef for their full pelagic period. Accordingly, the prevailing view that self-seeding is unlikely to be an important aspect of the ecology of coral reef organisms is inadequate. Indeed, it is possible from the model results to identify circumstances in which self-seeding of a reef may be the most important mechanism for recruitment on particular coral reefs.

Rates of local retention will vary at a number of timescales, since the probability of recruitment to the natal reef changes with coastal current strength relative to reef size. Because of the measured variability in current strengths, local recruitment will vary with the coastal currents from one spawning period to the next.

Hence, it is plausible to postulate that population 
outbreaks of crown-of-thorns starfish (Moran 1986) are related to periods when currents were low during spawning, causing a relatively high retention and subsequent recruitment. On large reefs, this outcome may occur under a wide variety of weather conditions, whereas small reefs may be unable to retain larvae for more than a few days

The retention of larvae will also vary according to their position in the water column. Most marine larvae are denser than water and use a wide variety of mechanisms (e.g. parachute structures, positive and negative phototaxis and geotaxis, and density-reducing and passive hydrodynamic devices) to maintain or alter their positions (Chia et al. 1984, Keough 1988). Unfortunately, there are very few data about these features for coral reef organisms; one possible exception is the larvae of crown-of-thorns starfish which have exhibited geonegative and photopositive behaviour in the laboratory (Moran 1986). Despite this general lack of information, the model results are the first to give quantitative indications of the consequences of occupying different levels in the water column. For example, the average residence times for buoyant larvae, which occupy the top of the water column (e.g. eggs and early larvae of corals which are positively buoyant for several days; Oliver \& Willis 1987) will generally be lower than those which are neutrally buoyant (e.g. Acanthaster planci, Olson pers. comm., Moran pers. obs.; Trochus niloticus, Nash 1985), or those which are negatively buoyant (e.g. most marine larvae, especially at later stages; Chia et al. 1984). Moreover, the probabilities of retention can be expected to increase by as much as an order of magnitude if the larvae spend most of their time near the sea bed.

The positions of larvae in the water column also can vary as a result of actively swimming. For example, larvae of coral reef fish are known to move upwards during the day and downwards at night (Leis 1986). This type of behaviour will greatly affect the probability of larval retention or dispersal. Data collected by Mileikovsky (1973) and Chia et al. (1984) indicate that most larvae, except those of ascidians and late-stage larva of crustaceans and cephalopods, have swimming speeds in the range of $<0.001$ to $0.01 \mathrm{~m} \mathrm{~s}^{-1}$, with most distributed at the lower end. Mileikovsky concluded that only a relatively small proportion of marine larvae would be unable to regulate their vertical distribution by swimming, even in strong currents. The vertical location of the centre of mass of a patch of larvae may be eventually altered by persistent upward or downward swimming. However, in coral reef environments where strong currents occur in relatively deep water over varying bathymetry, the time scales for travel between the bed and surface can be relatively long. In addition, for typical horizontal speeds of 0.1 to $0.3 \mathrm{~m}$ $\mathrm{s}^{-1}$, turbulent vertical speeds are expected to be around 0.001 to $0.015 \mathrm{~m} \mathrm{~s}^{-3}$. As well as reducing the average net velocity of a patch of larvae, this turbulence may prevent weak swimmers from maintaining their orientation in the water column. On the GBR, therefore, larvae with swimming speeds at the lower end of the range, such as those of Acanthaster planci (Yamaguchi 1973), are individually unlikely to be able to maintain themselves at a preferred level in the water column. Larvae of coral reef species which are approximately neutrally buoyant and/or weak swimmers can be expected to behave in an essentially passive manner in the water column.

Whether or not larvae are dispersed away from their natal reef will depend also on when spawning takes place. On the GBR, many corals (e.g. Babcock et al. 1986) spawn synchronously 4 to $5 \mathrm{~d}$ after the full moon in late spring. The gastropod Trochus niloticus (Nash 1985) spawns in synchrony with the lunarcycle, while most fish (Sale 1980) and some asteroids (e.g. Acanthaster planci Babcock 1990) seem not to. Other corals appear to spawn during neap or low-amplitude tides (Stimson 1978, Kojis \& Quinn 1982, Babcock et al. 1986) and some fish are known to spawn on a turning tide (Sale 1980).

Some authors (e.g. Stimson 1978, Kojis \& Quinn 1982) have suggested that release of propagules during low or neap tides will facilitate larval retention. Our results indicate that more retention may occur during high or spring tides on reefs. While the increased tidal excursion should result in greater losses (Black et al. 1990), the non-linear interaction due to bed friction on the tidal flat plays an opposing role, causing material to be retained. Eddies in the lee of the reef also strengthen with tidal amplitude causing particles to be retained. Moreover, on a regional scale, coastal currents on the continental shelf may be reduced during spring tides by the nonlinear interaction through the bed friction term. Ultimately, the balance between these factors will determine when larval retention is greater.

\section{Internal and external sources}

The significance of the demonstrations of self-seeding potential can be assessed by comparisons with the capacity of reefs to capture larvae advected from upstream reefs. 2-dimensional simulations with a moderate coastal current showed that only $3 \%$ of larvae entering the model grid upstream of Davies Reef (at release numbers equal to those for simulations of within-reef releases) were retained after $10 \mathrm{~d}$, compared with $45 \%$ for the within-reef release. In this case, the interaction of hydrodynamic components results in capture of fewer larvae from upstream reefs than were retained from the natal reef. 
The volume of water entering the region of the reef is necessarily equal to the volume lost. Thus, if a reef has a long retention time we can expect that less material from upstream reefs will enter the region of the reef. In reality, currents flow around rather than onto reefs with high retention. Excluding surface flows which are more strongly dependent on wind strength, much inter-reef material will travel past a reef in the adjacent deep water. Clustered reefs are an exception. High inter-reef exchange within clustered reefs can be expected to occur when the reefs are close together, especially if they are within one tidal excursion of one another, making it possible to consider the clustered reefs as a large, single unit.

In the lee of clustered reefs, the coastal currents are expected to be reduced. Larvae are therefore more likely to be retained at a reef cluster scale. The reef simulated in this paper, Davies Reef, is a medium-sized reef situated in the central section of the GBR where reef density is less than in other zones and where coastal currents are relatively fast. These factors suggest that other parts of the GBR or larger reef groups could have a higher probability of self-seeding, including the northern part of the Cairns Section where Dight \& James (1988) noted that net flows were slower and in the Cairns section where reefs are closer together. Thus, while retention is possible in the central GBR, even on exposed common-sized reefs and particularly on the larger reefs in the region, higher levels of retention may occur elsewhere on the GBR.

The numerical modelling and the assessment of the implications of the results with regard to GBR ecology and biology indicate that parent reefs may provide a highly important source of recruiting larvae, even when times in the plankton are the order of weeks. Larvae are undoubtedly lost from these reefs to downstream (the loss rate is dependent on reef size and coastal current strength) and some of these larvae must successfully settle. The results of the retention studies, however, suggest that the alternative, that of local retention, is very important under identifiable circumstances.

Acknowledgements. This work was funded by the Great Barrier Reef Marine Park Authority and the Victorian Institute of Marine Sciences. The authors thank John Parslow, Peter Doherty and Jason Middleton for their comments on the original version of the manuscript.

\section{LITERATURE CITED}

Andrews, J. C. (1983). Lagoon-ocean interaction. In: Baker, J. T., Carter, R. M., Sammarco, P. W., Stark, K. P. (eds.). Proceedings of the Great Barrier Conference. James Cook University Press, Townsville, p. 403-408

Andrews, J. C., Bode, L. (1988). The tides of the Central Great Barrier Reef. Cont. Shelf Res. 8: 1057-1085
Andrews, J. C., Dunlap, W. C., Bellamy, N. F. (1984). Stratification in a small lagoon in the Great Barrier Reef. Aust. J. mar Freshwat. Res. 35: 273-284

Andrews, J. C., Gentien, P. (1982). Upwelling as a source of nutrients for the Great Barrier Reef ecosystems: a solution to Darwin's question? Mar. Ecol. Prog. Ser. 8: 257-269

Babcock, R. C., Bull, G. D., Harrison, P. L., Heyward, A. J., Oliver, J. K., Wallace, C. C., Willis, B. L. (1986). Synchronous spawnings of 105 scleractinian coral species on the Great Barrier Reef. Mar. Biol. 90: 379-394

Babcock, R. C. (1990). Spawning behaviour of Acanthaster planci. Coral Reefs 9: 124

Black, K. P. (1983). Sediment transport and tidal inlet hydraulics. D. Phil. thesis, Univ of Waikato, New Zealand, Vols. 1 and 2

Black, K. P. (1988). The relationship of reef hydrodynamics to variations in numbers of planktonic larvae on and around coral reefs. Proc. 6th Int. Coral Reef Symp., Townsville 2: $125-130$

Black, K. P. (1989). Numerical simulation of steady and unsteady meso-scale eddies. Proc. 9th Australasian Coastal and Ocean Eng. Conf. Australian Inst. Eng., Adelaide, p. 204-208

Black, K. P. (1990). Hydrodynamics and salt transport in an estuarine channel. Part 3: Numerical model. Vict. Inst. Mar. Sci. Tech. Rep. 11, 28 p.

Black, K. P., Gay, S. L. (1987a). Eddy formation in unsteady flows. J. geophys. Res. 92 (C9): 9514-9522

Black, K. P., Gay, S. L. (1987b). Hydrodynamic control of the dispersal of crown-of-thorns starfish larvae 1. Small-scale hydrodynamics on and around schematized and actual coral reefs. Vict. Inst. Mar. Sci. Tech. Rep. 8, 62 p.

Black, K. P., Gay, S. L. (1990a). Reef-scale numerical hydrodynamic modelling developed to investigate crown-ofthorns starfish outbreaks. In: Bradbury, R. (ed.) Acanthaster in the coral reef: a theoretical perspective. Lecture notes in Biomathematics, Springer-Verlag, Berlin, p. $120-150$

Black, K. P., Gay, S. L. (1990b). A numerical scheme for determining trajectories in particle models. In: Bradbury, R. (ed.) Acanthaster in the coral reef: a theoretical perspective. Lecture notes in Biomathematics, Springer-Verlag, Berlin, p. 151-156

Black, K. P., Gay, S. L., Andrews, J. C. (1990). A method to determine residence times of neutrally-buoyant matter such as larvae, sewage or nutrients on coral reefs. Coral Reefs 9 (3): 105-114

Black, K. P., Healy, T. R. Hunter, M. (1989). Sediment dynamics in the lower section of a mixed sand and shelllagged tidal estuary. J. coast. Res. 5 (3): 503-521

Black, K. P., Moran, P. D. (1991). Influence of hydrodynamics on the passive dispersal and initial recruitment of larvae of Acanthaster planci (Echinodermata: Asteroidea) on the Great Barrier Reef. Mar. Ecol. Prog. Ser. 69: 55-65

Cheney, D. P. (1974). Spawning and aggregation of Acanthaster planci in Micronesia. Proc. 2nd Int. Coral Reef Symp. 1: 591-594

Chia, F.-S., Buckland-Nicks, J., Young, C. M. (1984). Locomotion of marine invertebrate larvae: a review. Can. J. Zool. 62: 1205-1222

Church, J. A., Andrews, J. C., Boland, F. M. (1985). Tidal currents in the Central Great Barrier Reef. Cont. Shelf Res. 4: $515-531$

Dight, I. J., James, M. K. (1988). Simulations of large-scale population dynamics of crown of thorns starfish in the Great Barrier Reef system. Res. Bull. CS36, Civil and Systems Eng., James Cook University, Townsville, 38 p. 
Dyer, K. R. (1973). Estuaries: a physical introduction. WileyInterscience, London

Fadallah, Y H. (1983). Sexual reproduction, development and larval biology in scleractinian corals. A review. Coral Reefs 2: $129-150$

Gay, S. L., Andrews, J. C., Black, K. P. (1990). Dispersal of neutrally-buoyant material near John Brewer Reef. In: Bradbury, R. (ed.) Acanthaster in the coral reef: a theoretical perspective. Lecture notes in Biomathematics, Springer-Verlag, Berlin, p. 95-119

Hamner, W. M. Hauri, I. R. (1981). Effects of island mass: water flow and plankton pattern around a reef in the Great Barrier Reef lagoon, Australia. Limnol. Oceanogr 26: $1084-1102$

Harrison, P. L., Babcock, R. C., Bull, G. D., Oliver, J. K., Wallace, C. C., Willis, B. L. (1984). Mass spawning in tropical reef corals. Science 223: 1186-1189

Johannes, R. E. (1978). Reproductive strategies of coastal marine fishes in the tropics. Environ. Biol. Fish. 3: 65-84

Keough, M. J. (1988). Benthic populations: is recruitment limiting or just fashionable? Proc. 6th Int. Coral Reef Symp., Townsville 1: 141-148

Kojis, B. L., Quinn, N. J. (1982). Reproductive ecology of two saviid corals (Coelenterata: Scleractinia). Mar. Ecol. Prog. Ser. 8: 251-255

Leendertse, J. J., Liu, S.-K. (1975). Modelling of three-dimensional flows in estuaries. Proc. 2nd Annual Symposium on Modelling Techniques. Waterways, Harbours and Coastal Engineering (Div. ASCE), p. 625-642

Leis, J. M. (1986). Vertical and horizontal distribution of fish larvae near coral reefs at Lizard Island, Great Barrier Reef. Mar. Biol. 90: 505-516

Ludington, C. A. (1981). A study of flushing and exchange in reef lagoons using fluorescent dye. Proc. Conf. on Environmental Eng. Townsville. James Cook Univ. Press, p. 102-106

Mileikovsky, S. A. (1973). Speed of active movement of pelagic larvae of marine bottom invertebrates and their ability to regulate their vertical position. Mar. Biol. 23: $11-17$

Moran, P. J. (1986). The Acanthaster phenomenon. Oceangr mar Biol. Ann. Rev. 24: 379-480

Munro, J. L., Williams, D. McB. (1985). Assessment and management of coral reef fisheries: biological, environmental and socio-economic aspects. Proc. 5th int. Coral Reef Congr. 4: $545-578$

Nash, W. J. (1985). Aspects of the biology of Trochus niloticus and its fishery in the GBR region. Rep. to Fisheries Res. Branch, Queensland Dept Primary Industries and the

This article was presented by P. W. Sammarco, Canberra, Australia
Great Barrier Marine Park Authority Northern Fisheries Res. Cent, Cairns, 204 p.

Oliver, J. K., Willis, B. L. (1987). Coral spawn slicks in the Great Barrier Reef; preliminary observations. Mar Biol. 94: 521-529

Olson, R. R. (1987). In situ culturing as a test of the larval starvation hypothesis for the crown-of-thorns starfish, Acanthaster planci. Limnol. Oceanogr. 32: 895-904

Pickard, G. L., Donguy, R. H., Henin, C., Rougerie, F. (1977). A review of the physical oceanography of the Great Barrier Reef and Western Coral Sea. Aust. Inst. Mar Sci. Monogr Ser. 2

Sale, P. F. (1980). The ecology of fishes on coral reefs. Oceanogr mar Biol. Ann. Ref. 18: 367-421

Sammarco, P. W., Andrews, J. C. (1988). Localised dispersal and recruitment in Great Barrier Reef corals: The Helix Experiment. Science 239: 1422-1424

Stimson, J. S. (1978). Mode and timing of reproduction in some common hermatypic corals of Hawaii, Enewetok. Mar. Biol. 48: 173-184

Willis, B. L., Oliver, J. K. (1988). Distribution of coral eggs and larvae in the central section of the Great Barrier Reef marine park following the annual mass spawning of corals. Rept. to Great Barrier Reef Marine Park Authority, Townsville, $49 \mathrm{p}$

Wolanski, E., Burrage, D., King, B. L. (1989). Trapping and dispersion of coral eggs around Bowden Reef, Great Barrier Reef, following mass coral spawning. Cont. Shelf Res. 9: $479-496$

Wolanski, E., Hamner, W. M. (1988). Topographically controlled fronts in the ocean and their biological influence. Science $241 \quad 177-181$

Wolanski, E., Imberger, J., Heron, M. L. (1984a). Island wakes in shallow coastal waters. J. geophys. Res. 89: 10553-10569

Wolanski, E., Pickard, G. P. (1983). Currents and flushing of Britomart Reef Lagoon, Great Barrier Reef. Coral Reefs 2: $1-8$

Wolanski, E., Pickard, G. P., Jupp, D. L. B. (1984b). River plumes, coral reefs and mixing in the Gulf of Papua and the northern Great Barrier Reef. Estuar coast. Shelf Sci. 18: 291-314

Yamaguchi, M. (1973). Early life histories of coral reef asteroids, with special reference to Acanthaster planci (L.) In: Jones, O. A., Endean, R. (eds.) Biology and geology of coral reefs. Academic Press, New York, p. 369-387

Yamaguchi, M. (1977). Larval behaviour and geographic distribution of coral reef asteroids in the Indo-West Pacific. Micronesica 13: 283-296

Manuscript first received: November 23, 1990

Revised version accepted: April 26, 1991 